\title{
Influence of host plant on susceptibility of the aphid Acyrthosiphon pisum (Hemiptera: Aphididae) to the fungal pathogen Pandora neoaphidis (Zygomycetes: Entomophthorales)
}

\author{
Cezary TKaCZUK ${ }^{1}$, Paresh A. ShaH ${ }^{2}$, Suzanne J. ClarK ${ }^{3}$ and Judith K. PELL ${ }^{2 *}$ \\ ${ }^{1}$ Department of Plant Protection, University of Podlasie, Prusa 14, 08-110 Siedlce, Poland \\ ${ }^{2}$ Plant and Invertebrate Ecology Division, ${ }^{3}$ Biomathematics and Bioinformatics Division, Rothamsted Research, Harpenden, \\ Hertfordshire AL5 2JQ, UK; e-mail: judith.pell@bbsrc.ac.uk
}

Key words. Hemiptera, Aphididae, Zygomycetes, Entomophthorales, Acyrthosiphon pisum, Pandora neoaphidis, host plant, tritrophic interactions, natural enemies

\begin{abstract}
The performance of the aphid-specific fungal pathogen Pandora neoaphidis was studied in relation to changes in herbivore resources for the pea aphid, Acyrthosiphon pisum, on different host plant species. Dose-response bioassays were conducted with A. pisum which had been reared on dwarf bean then inoculated with $P$. neoaphidis and returned to dwarf bean or inoculated and transferred to field bean, pea or lucerne. The smallest estimated median lethal concentration $\left(\mathrm{LC}_{50}\right)$ was 7.7 conidia $\mathrm{mm}^{-2}(95 \%$ confidence interval 5.4-11.2) for aphids returned to dwarf bean, with $\mathrm{LC}_{50} \mathrm{~s}$ of $13.0(9.2-19.1)$ and $14.6(10.2-21.5)$ conidia $\mathrm{mm}^{-2}$ for

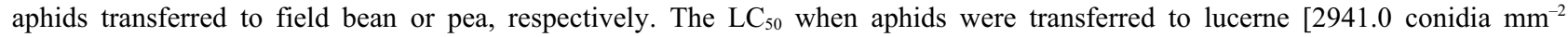
$\left(237.3-2.1 \times 10^{9}\right)$ ] was greater than for the other three plants. In a subsequent experiment, A. pisum were reared on pea as well as dwarf bean for four generations before bioassays. The $\mathrm{LC}_{50}$ was 7.3 conidia $\mathrm{mm}^{-2}$ (4.4-12.4) for aphids reared and incubated on dwarf bean, compared to $13.3(8.0-23.9)$ and $15.3(8.8-29.9)$ conidia $\mathrm{mm}^{-2}$ when aphids were transferred between dwarf bean and pea, and vice versa, respectively. The $\mathrm{LC}_{50}$ for aphids reared then incubated on pea plants was 27.9 (15.8-57.3) conidia mm $\mathrm{mm}^{-2}$. Hence, the virulence of $P$. neoaphidis, measured by $\mathrm{LC}_{50}$, was greatest when $A$. pisum was reared and maintained on dwarf bean, the plant used for long-term routine culturing of the aphid in our facilities. In conclusion, virulence of $P$. neoaphidis was greater on plant species to which $A$. pisum had become adapted during long-term laboratory rearing. Plant resources may affect infection by $P$. neoaphidis and the fungal entomopathogen will have a greater impact on aphid herbivores which are not suffering physiological stress related to a change in host plant.
\end{abstract}

\section{INTRODUCTION}

Studies of tritrophic interactions aim to understand the often complex relationships between plants, herbivores and natural enemies. They can be used to explain patterns of association in natural communities and may suggest better methods for sustainable pest control in agricultural crops (Agrawal, 2000; Giles et al., 2002). Plants can affect performance of herbivore natural enemies positively or negatively through modified features such as chemistry (volatiles, secondary compounds), resources (nectar, pollen) and/or morphology (trichomes, domatia) (e.g. Kareiva \& Sahaklan, 1990; Takabayashi \& Dicke, 1996; Agrawal et al., 2000; Cortesero et al., 2000; Walker \& Jones, 2001; Kessler \& Baldwin, 2002; Cory \& Hoover, 2006). Density-dependent regulation of herbivore populations is equally likely to be caused by plant attributes as by the action of natural enemies (Stiling, 1988). In addition, the direction and scale of tritrophic interactions can be affected by abiotic conditions (e.g. Gonzáles et al., 2002; Paul \& Gwynn-Jones, 2003), and may vary within a growing season (Gratton \& Denno, 2003).

Aphids are a widespread and diverse group of plant herbivores. Approximately 4000 species have been described, with the greatest species numbers and abundances occurring in temperate regions of the world, where approximately $25 \%$ of plant species are food resources for aphids (Dixon, 1998). Adaptation by many aphid species to marked seasonality and ephemeral summer host resources includes polyphenism (sexual, asexual forms) and telescoping of generations in parthenogenic summer females (Dixon, 1998). Alternation between different host plant species is a necessary strategy for population survival within and between seasons. In general, the feeding strategies and gut physiology of aphids, as with other sap-sucking Hemiptera, are considered to have adapted to evade plant defence and wounding responses involving the polyphenol oxidase metabolic pathway (Gatehouse, 2002).

The effects of various predators, parasitoids and fungal pathogens on aphids have been documented in laboratory and field studies, and simulation modelling studies of tritrophic interactions involving cereal aphids have been reported by Gosselke et al. (2001). Pandora neoaphidis (Remaudière et Hennebert) Humber (Zygomycetes: Entomophthorales) infects aphids of many different genera, and it can be an important regulatory factor limiting aphid populations (Pell et al., 2001; Shah et al., 2004). During

\footnotetext{
* Corresponding author.
} 
infection, conidia germinate and penetrate the aphid cuticle, after which fungal stages (protoplasts and hyphal bodies) circulate in the haemolymph and colonize host tissues. At $18^{\circ} \mathrm{C}$ death of the host occurs within four to seven days. Rhizoids then emerge to attach the cadaver to the substrate, and spore-bearing structures actively discharge conidia to restart the infection cycle (Brobyn \& Wilding, 1977; Butt et al., 1990; Hemmati et al., 2001).

There have been few studies on interactions between plant species, aphids and $P$. neoaphidis, with the exception of investigations involving wheat varieties and the cereal aphid Sitobion avenae (Fabricius) (FuentesContreras et al., 1998; Fuentes-Contreras \& Niemeyer, 2000), and intraspecific variation in the pea aphid, Acyrthosiphon pisum Harris, to fungal infection from maternal lines initially collected from different non-crop plant species (Ferrari et al., 2001; Ferrari \& Godfray, 2003, 2006).

The objectives of the work reported here were to determine whether host plant species affected susceptibility of $A$. pisum to $P$. neoaphidis. The findings are discussed within the context of implications for $P$. neoaphidis population dynamics.

\section{MATERIAL AND METHODS}

\section{Insects and plants}

All aphids were maintained on selected host plant species in ventilated cages at $18^{\circ} \mathrm{C}$ and $70 \% \mathrm{RH}$ with a $16 \mathrm{~L}: 8 \mathrm{D}$ regime. Apterous adult aphids (2-3 days old) were used in all experiments. All plants were grown in a peat-loam mix ( $\mathrm{pH}$ 5.5-6.0; Petersfield Products, Leicester, England) in a greenhouse at $20^{\circ} \mathrm{C}$.

For routine culturing, A. pisum was reared on dwarf bean (Vicia faba (L.), variety "The Sutton"). For the purposes of some experiments, aphids were reared on an alternative host plant, the pea (Pisum sativum L., variety "Kelvedon Wonder") for one month (approximately three to five generations). Similar short-term adaptation periods to different plants have been considered sufficient to dissipate maternal and grand-maternal effects due to host plant origin and to ensure physiological adaptation to the test host (Ferrari \& Godfray, 2003; Vorburger et al., 2003).

\section{Pandora neoaphidis cultures}

Strain X4 (= isolate NW 327) of P. neoaphidis, originally obtained from infected $A$. pisum aphids on Rothamsted Farm, Hertfordshire, UK, was used in bioassays. This isolate was maintained as an in vivo culture by regular passage through adult apterous $A$. pisum, and recently killed, infected aphids were dried and stored at $20 \% \mathrm{RH}$ and $4{ }^{\circ} \mathrm{C}$ (Wilding, 1973). Cadavers were used within four weeks of preparation.

\section{Inoculation of aphids with fungal conidia and susceptibility of $\boldsymbol{A}$. pisum transferred between host plants}

Two sets of dose-response experiments were conducted. In experiment one, A. pisum was reared on dwarf bean ("The Sutton"), then groups of approximately ten apterae were exposed to conidia showers in inoculation chambers for $1,3,6,15,30$ or 60 min before transfer and incubation on either dwarf bean, field bean ( $V . f a b a$, variety "Alfred"), pea ( $P$. sativum, variety "Kelvedon Wonder") or lucerne (Medicago sativa L., variety "Euver"). Each inoculation chamber consisted of an open-ended glass cylinder $(5 \times 2 \mathrm{~cm})$, placed perpendicular to the base of a plastic Petri dish (50 mm diameter). Three sporulating cadavers on damp sponge were placed at the top of the inoculation chamber and showered conidia down on to the aphids within the chamber. A $13 \mathrm{~mm}$ diameter glass cover slip was placed at the centre of the base of each inoculation chamber in order to estimate the concentration of conidia produced during the inoculation period and thereby estimate the dose received by the aphids. Two separate inoculation chambers (i.e. a total of approximately 20 aphids) were used for each exposure period, and control aphids for each plant type were maintained in chambers without fungal exposure for the longest inoculation period, i.e. $60 \mathrm{~min}$. Aphids were incubated in a plant growth chamber $\left(18^{\circ} \mathrm{C}, 18 \mathrm{~L}: 6 \mathrm{D}\right)$ on appropriate test plants after fungal exposure. Plants were kept under high humidity $(>90 \% \mathrm{RH})$ for the first $24 \mathrm{~h}$ to ensure conidia germination. After $24 \mathrm{~h}$, any dead aphids were removed and excluded from data analysis as their mortality was associated with handling. Remaining aphids were examined daily for seven days and any dead aphids removed and placed in humid chambers to determine if sporulation by $P$. neoaphidis occurred within $24 \mathrm{~h}$. In this experiment, dwarf bean represented the "original" host plant while field bean, lucerne and pea were "alternative" food plants for A. pisum. Bioassays were repeated on four occasions, using a total of 192 inoculation chambers and 1680 aphids.

In experiment two, apterae of A. pisum reared on dwarf bean or pea ("Kelvedon Wonder") for one month prior to experiments, were exposed, as described previously, in groups of ten, to conidia showers for 1, 3, 6, 15, 30 or $60 \mathrm{~min}$, followed by transfer and incubation on either dwarf bean or pea. As before, there were two inoculation chambers for each exposure period and control aphids for each plant type were left without fungus in chambers for the longest inoculation period, i.e. 60 min. After fungal exposure, aphids were incubated on appropriate test plants in a plant growth chamber as described previously and mortality assessed daily for seven days. The four possible combinations of "original" and "alternative" host and food plants were tested. Hence, comparisons were made between aphids reared on dwarf bean then returned to dwarf bean or transferred to pea, and aphids reared on pea then returned to pea or transferred to dwarf bean. Mortality was assessed daily and dead aphids were placed in humid chambers to check if infection by $P$. neoaphidis had occurred. For each replicate there was an average of 8.2 apterae $(\mathrm{SE}=0.13)$. The bioassays were repeated on three occasions, using a total of 144 inoculation chambers and 983 aphids.

\section{Statistical analyses}

All statistical analyses were done using the GenStat statistical package (Payne, 2003). The final proportions of dead A. pisum infected by $P$. neoaphidis at the end of seven days per occasion (replicate) were related to the concentration of conidia applied using a generalized linear model with binomial error and probit link (McCullagh \& Nelder, 1989). Where overdispersion was indicated by a residual mean deviance significantly greater than unity, ratios of treatment to residual mean deviances were compared against the F-distribution. Numbers of conidia applied (estimated concentration) were logged (base 10) before analysis. For each food plant (experiment one) or original host/alternative food plant combination (experiment two), an initial parallel model probit analysis was done to determine whether replicate results from different assays could be combined. First, a single probit line was fitted to data from all assays. Second, intercepts were allowed to vary between assays. Third, slopes were also allowed to vary between assays. As the single line model was generally adequate (data not shown), data from the different assays were pooled for each treatment combination and similar 
TABLE 1. Results of assays with Acyrthosiphon pisum reared on dwarf bean and incubated on different food plants after exposure to Pandora neoaphidis conidia. $\mathrm{LC}_{50}$ (conidia $\mathrm{mm}^{-2}$ ) with $95 \% \mathrm{CI}$ in parentheses.

\begin{tabular}{cccc}
\hline Food plant & $\mathrm{LC}_{50}(95 \% \mathrm{CI})$ & $a(\mathrm{SE})$ & $b(\mathrm{SE})$ \\
\hline Dwarf bean & 7.7 & -1.018 & 1.145 \\
("The Sutton") & $(5.4-11.2)$ & $(0.108)$ & $(0.086)$ \\
Field bean & 13.0 & -1.277 & $"$ \\
("Alfred") & $(9.2-19.1)$ & $(0.115)$ & $"$ \\
Pea & 14.6 & -1.333 & 0.523 \\
("Kelvedon Wonder") & $(10.2-21.5)$ & $(0.118)$ & $(0.184)$ \\
Lucerne & 2941.0 & -1.812 & $(0.210)$ \\
\hline
\end{tabular}

$a$ and $b$ are intercept and regression coefficient, respectively, from a generalized linear model regression (with binomial error and logit link) of proportion infected aphids after seven days on concentration of conidia applied. $\mathrm{LC}_{50}$ values based on data pooled over four assays for each host plant species and computed from a reduced model indicating different overall levels of infection for each treatment but a common dose-response relationship for the three non-lucerne treatments which differed to that for lucerne.

parallel model analyses were done to compare treatments within each experiment. For experiment one, the overall treatment effect was partitioned to represent contrasts between lucerne and the other food plants combined, and differences amongst the three non-lucerne treatments. For experiment two the factorial treatment structure was incorporated to test overall differences between the two "original" host plants and between the two "alternative" food plants, and to see if any interaction existed between these two factors. Median lethal concentration $\left(\mathrm{LC}_{50}\right)$ estimates were obtained from best fit models and confidence intervals $(\mathrm{CI})$ for $\mathrm{LC}_{50}$ values were calculated according to Fieller's theorem (see Finney, 1971). LC $_{50}$ estimates and 95\% CIs are presented back-transformed from the logarithmic scale.

\section{RESULTS}

\section{Transfer of $A$. pisum between host plants}

In experiment one where $A$. pisum was reared on dwarf bean then transferred to different food plants after exposure to $P$. neoaphidis, overall mortality in control groups of aphids was $0 \%$ for $A$. pisum returned to dwarf bean, $10.0 \%(\mathrm{SE}=3.35)$ for field bean, $16.3 \%(\mathrm{SE}=4.12)$ for pea and $92.5 \%(\mathrm{SE}=2.94)$ for lucerne. The second stage probit regressions indicated an overall dose-response relationship $\left(\mathrm{F}_{1,183}=198.58, \mathrm{p}<0.001\right)$ but with differing intercepts $\left(\mathrm{F}_{1,183}=100.84, \mathrm{p}<0.001\right)$ and slopes $\left(\mathrm{F}_{1,183}=\right.$ $8.05, \mathrm{p}=0.005$ ) for lucerne (Table 1) and the combined group of species. Within the combined group the overall level of infection differed amongst the three species $\left(\mathrm{F}_{2,183}\right.$ $=3.58, \mathrm{p}=0.030$; Table 1) but there was little evidence of non-parallelism $\left(\mathrm{F}_{2,183}=2.61, \mathrm{p}=0.076\right)$. When aphids were transferred to lucerne the estimated LC $_{50}$ (2941 conidia $\mathrm{mm}^{-2}, n=47$ ) was far greater than when aphids were transferred to any other food plant. The smallest $\mathrm{LC}_{50}$ was determined for dwarf bean ( 7.7 conidia $\mathrm{mm}^{-2}, n$ $=48)$. $\mathrm{LC}_{50}$ values for pea and field bean were $14.6(n=$ $48)$ and $13.0(n=48)$ conidia $\mathrm{mm}^{-2}$, respectively (Table 1). The slope of the probit regression line common to dwarf bean, field bean and peas was close to unity but the slope for lucerne was much shallower suggesting that dose has less effect on infection of A. pisum feeding on this food plant (Table 1).

In experiment two where A. pisum was reared on dwarf bean or pea and transfers were made between these two plants, overall mortality in control aphids was $12.5 \%$ (SE $=6.78$ ) for the dwarf bean-dwarf bean combination and $0 \%$ in the pea-pea combination, while control mortalities were $3.8 \%(\mathrm{SE}=3.77)$ and $4.5 \%(\mathrm{SE}=4.44)$ for the dwarf bean-pea and pea-dwarf bean tests, respectively. A constrained parallel line model best described the data; there was no evidence of non-parallelism (all three concentration interaction terms $\mathrm{p}>0.05)$. There was evidence of an overall dose-response relationship $\left(\mathrm{F}_{1,82}=\right.$ $100.49, \mathrm{p}<0.001)$ with one common slope, close to

TABLE 2. Results of assays with Acyrthosiphon pisum reared on dwarf bean or pea (original host plant) and incubated on either dwarf bean or pea (alternative food plant) after exposure to Pandora neoaphidis conidia. $\mathrm{LC}_{50}$ (conidia $\mathrm{mm}^{-2}$ ) with $95 \% \mathrm{CI}$ in parentheses.

\begin{tabular}{|c|c|c|c|c|}
\hline Original host plant & Alternative food plant & $\mathrm{LC}_{50}(95 \% \mathrm{CI})$ & $a(\mathrm{SE})$ & $b(\mathrm{SE})$ \\
\hline $\begin{array}{l}\text { Dwarf bean } \\
\text { ("The Sutton") }\end{array}$ & $\begin{array}{l}\text { Dwarf bean } \\
\text { ("The Sutton") }\end{array}$ & $\begin{array}{c}7.3 \\
(4.4-12.4)\end{array}$ & $\begin{array}{l}-0.989 \\
(0.154)\end{array}$ & $\begin{array}{l}1.146 \\
(0.129)\end{array}$ \\
\hline $\begin{array}{l}\text { Dwarf bean } \\
\text { (“The Sutton") }\end{array}$ & $\begin{array}{c}\text { Pea } \\
\text { (“Kelvedon Wonder”) }\end{array}$ & $\begin{array}{c}13.3 \\
(8.0-23.9)\end{array}$ & $\begin{array}{l}-1.288 \\
(0.166)\end{array}$ & " \\
\hline $\begin{array}{c}\text { Pea } \\
\text { ("Kelvedon Wonder") }\end{array}$ & $\begin{array}{l}\text { Dwarf bean } \\
\text { ("The Sutton") }\end{array}$ & $\begin{array}{c}15.3 \\
(8.8-29.9)\end{array}$ & $\begin{array}{l}-1.357 \\
(0.160)\end{array}$ & " \\
\hline $\begin{array}{c}\text { Pea } \\
\text { (“Kelvedon Wonder") }\end{array}$ & $\begin{array}{c}\text { Pea } \\
\text { (“Kelvedon Wonder") }\end{array}$ & $\begin{array}{c}27.9 \\
(15.8-57.3)\end{array}$ & $\begin{array}{l}-1.656 \\
(0.167)\end{array}$ & " \\
\hline
\end{tabular}

$a$ and $b$ are intercept and regression coefficient, respectively, from a generalized linear model regression (with binomial error and logit link) of proportion infected aphids after seven days on concentration of conidia applied. $\mathrm{LC}_{50}$ values based on data pooled over three assays for each plant species and computed from a constrained parallel line model indicating different overall levels of infection but a common dose-response relationship for each treatment combination. 
unity, for the four different host/food plant combinations (Table 2). However, intercepts differed between the two original host plants $\left(\mathrm{F}_{1,82}=5.98, \mathrm{p}=0.017\right)$ and, independently, between the two alternative food plants $\left(\mathrm{F}_{1,82}=\right.$ $4.63, \mathrm{p}=0.034)$, as there was no interaction between these factors $\left(\mathrm{F}_{1,82}=0.65, \mathrm{p}=0.423\right)$. The $\mathrm{LC}_{50}$ for aphids reared and incubated on dwarf bean $\left(7.3\right.$ conidia $\mathrm{mm}^{-2}, n$ $=21$ ) was smaller than for aphids reared and incubated on pea (27.9 conidia $\left.\mathrm{mm}^{-2}, n=23\right)$. There was evidence for a decrease in susceptibility when aphids reared on dwarf bean were transferred to pea rather than dwarf bean, and an equivalent increase when aphids reared on pea were transferred to dwarf bean rather than pea (difference in intercepts for alternative pea and bean in each case $=$ -0.299 , sed $=0.150, \mathrm{t}(86)=-2.00, \mathrm{P}=0.049)$. The resulting $\mathrm{LC}_{50} \mathrm{~S}$ for aphids reared on pea and transferred to dwarf bean and for aphids reared on dwarf bean and transferred to pea were 15.3 conidia $\mathrm{mm}^{-2}(\mathrm{n}=24)$ and 13.3 conidia $\mathrm{mm}^{-2}(\mathrm{n}=22)$, respectively (Table 2$)$.

\section{DISCUSSION}

The null hypothesis for experiments reported here was that there were no differences in the susceptibility of aphids to $P$. neoaphidis when maintained on different food plants. Departures from this hypothesis may indicate that plant resources influence infection by $P$. neoaphidis, which may have implications for aphid-natural enemy dynamics at individual and population levels.

The experiments with $A$. pisum showed that transferring apterae from original to alternative food plants changed aphid susceptibility to $P$. neoaphidis, as indicated by differing underlying probit lines and larger $\mathrm{LC}_{50}$ values for field bean and pea and, more markedly, for lucerne, compared to dwarf bean. There are three crop-feeding biotypes of $A$. pisum adapted to different host plants (pea/bean, clover and lucerne) and each biotype is considered to have reduced fitness on plants of the other two biotypes (Birkle \& Douglas, 1999). The extremely low infection obtained here with $A$. pisum on lucerne may partly be due to the high physiological stress suffered by apterae from a biotype which preferred to feed on dwarf bean. This may also be reflected in the high control mortality on lucerne compared with aphids on the three other plant species. Short-term adaptation and incubation of $A$. pisum on pea plants did not increase susceptibility to fungal infection when compared with A. pisum maintained and incubated on dwarf bean, the food plant used for routine aphid culturing. With respect to differences between host plant species, Ferrari et al. (2001) found variation in susceptibility of $A$. pisum collected from a range of plants including Vicia spp., P. sativum, large bird's foot trefoil (Lotus uliginosus Schkuhr) and red clover (Trifolium pratense L.). Infection by $P$. neoaphidis was smallest for $A$. pisum from $T$. pratense, and this resistance was not dependant on whether tests were carried out on clover or on the dwarf bean variety "The Sutton". In general, from these and other studies pea aphid clones appear to perform better (e.g. fecundity) on the original host plant genus from which they were originally collected (Ferrari \& Godfray, 2003, 2006).

We found a trend for increased susceptibility to infection in pea aphid on the Vicia food plant used in routine laboratory culturing, compared with alternative plants where the pea aphid had a shorter association time. Ferrari \& Godfray (2006) suggest that most pea aphid clones perform well on Vicia because the species initially evolved on Vicia and then radiated to other legume genera.

The ecological implications of differences in virulence of $P$. neoaphidis against aphids on different host plant species could include a mechanism for maintaining intraspecific diversity of the fungal pathogen, since different isolates of the fungus may vary in performance depending on plant resources, as has been indicated for baculovirus populations infecting lepidopteran larvae feeding on different plant species (Hodgson et al., 2002; Raymond et al., 2002). Conversely, variation in virulence of $P$. neoaphidis against aphids on different host plant species may effectively provide aphids with spatio-temporal refuges in mixed plant communities, particularly during seasonal shifts when aphids may be transferring between winter and summer plant species and varieties. The lack of susceptibility of aphids to $P$. neoaphidis when feeding on host plant species to which they have had only a shortterm adaptation may have two possible explanations. First, it could be a result of differences in plant physiology and chemistry (Fuentes-Contreras et al., 1998; Raymond et al., 2002). Studies have shown detrimental effects on entomopathogen performance caused by secondary plant compounds (e.g. Gallardo et al., 1990; Schultz \& Keating, 1991; Hajek \& Renwick, 1993; Brown et al., 1995; Inyang et al., 1999; Poprawski et al., 2000; Meekes, 2001). Phytochemicals, such as phenolics and other reactive products produced by plants during redox cycling, are hypothesised to alter many steps of the infection cycle by entomopathogens (Cory \& Hoover, 2006). Interestingly, plant volatiles can affect germination of $P$. neoaphidis conidia in different ways but they do not influence infectivity of this fungus to A. pisum (Baverstock et al., 2005) and Myzus nicotianae (Blackman) (Brown et al., 1995).

Another possibility is that aphid herbivores on alternative host plants may have experienced physiological stress while adapting to the new food resource, inhibiting host infection by $P$. neoaphidis. Milner \& Soper (1981) demonstrated that infection by a related fungal pathogen, Zoophthora radicans (Brefeld) Batko, was reduced when apterae of the spotted alfalfa aphid, Therioaphis maculata Buckton, were starved for $24 \mathrm{~h}$ prior to inoculation with fungal conidia compared with unstarved aphids. Stress in host insects seems to cause reduced infection by entomophthoralean fungi, such as $P$. neoaphidis and $Z$. radicans, and contradicts the generally accepted view that host stress should actually increase susceptibility to infection by entomopathogens (Steinhaus, 1949). Linked with this stress hypothesis could be the effects of facultative secondary endosymbiotic bacteria, which reside in bacte- 
riocytes alongside the primary endosymbionts, Buchnera spp., or which may circulate in the haemolymph (Montllor et al., 2002). Several studies have indicated associations between certain groups of secondary endosymbionts and aphid life history traits, including adaptations to host plant resources, moderation of abiotic stress factors and natural enemy resistance (e.g. Montllor et al., 2002; Tsuchida et al., 2002; Douglas et al., 2003). This work has been done with $A$. pisum as the model aphid species. In the current view of plant-herbivore-natural enemy tritrophic interactions, secondary endosymbionts may represent an additional internalised trophic level within aphid herbivores which needs to be more fully investigated.

There may be several potential problems in extending findings from this work to other aphid systems, such as the variation in susceptibility between different maternal lineages, or clones, which has been demonstrated for pea aphid (Ferrari et al., 2001; Ferrari \& Godfray, 2006). In this study, we only examined transfer of one aphid species between crop plants, but work has demonstrated similar effects of non-crop plants on $P$. neoaphidis and other aphid natural enemies (Ekesi et al., 2005).

In conclusion, performance of $P$. neoaphidis at the third trophic level is changed if aphid herbivores are feeding on a plant species to which they have a short-term, rather than long-term, association, possibly because of physiological stress in the host aphids. This may have implications for the development of $P$. neoaphidis in newly establishing populations of aphids derived from migrating alate aphids that have developed on different host plant species.

ACKNOWLEDGEMENTS. Research by PAS was sponsored by the Biotechnology and Biological Sciences Research Council of the UK (BBSRC), through the Sustainable Arable LINK Programme and conducted with support from the following industrial partners: Home Grown Cereals Authority (HGCA), Horticulture Development Council (HDC), Processors and Growers Research Organisation (PGRO), Sainsbury's plc, British Potato Council (BPC), and the National Institute for Agricultural Botany (NIAB). JKP was supported by the Department for Environment, Food and Rural Affairs of the UK (Defra). CT acknowledges financial assistance from the British Council. Rothamsted Research receives grant-aided support from BBSRC.

\section{REFERENCES}

Agrawal A.A. 2000: Mechanisms, ecological consequences and agricultural implications of tri-trophic interactions. Cur. Opin. Plant Biol. 3: 329-335.

Agrawal A.A., Karban R. \& Colfer R.G. 2000: How leaf domatia and induced plant resistance affect herbivores, natural enemies and plant performance. Oikos 89: 70-80.

Baverstock J., Elliot S.L., Alderson P.G. \& Pell J.K. 2005: Response of the entomopathogenic fungus Pandora neoaphidis to aphid-induced plant volatiles. J. Invertebr. Pathol. 89: 157-164.

Birkle L.M. \& Douglas A.E. 1999: Low genetic diversity among pea aphid (Acyrthosiphon pisum) biotypes of different plant affiliation. Heredity 82: 605-612.
BRobyn P.J. \& Wilding N. 1977: Invasive and developmental processes of Entomophthora species infecting aphids. Trans. Br. Mycol. Soc. 69: 349-366.

Brown G.C., Prochaska G.L., Hildebrand D.F., Nordin G.L. \& JACKSON D.M. 1995: Green leaf volatiles inhibit conidial germination of the entomopathogen Pandora neoaphidis (Entomophthorales: Entomophthoraceae). Envir. Entomol. 24: 1637-1643.

Butt T.M., Beckett A. \& Wilding N. 1990: A histological study of the invasive and developmental processes of the aphid pathogen Erynia neoaphidis (Zygomycotina: Entomophthorales) in the pea aphid Acyrthosiphon pisum. Can. J. Bot. 68: 2153-2163.

Cortesero A.M., Stapel J.O. \& Lewis W.J. 2000: Understanding and manipulating plant attributes to enhance biological control. Biol. Control 17: 35-49.

CORY J.S. \& Hoover K. 2006: Plant-mediated effects in insectpathogen interactions. Trends Ecol. Evol. 21: 278-289.

Dixon A.F.G. 1998: Aphid Ecology. 2nd ed. Chapman and Hall, London, $300 \mathrm{pp}$.

Douglas A.E., Darby A.C., Birkel L.M. \& Walters K.F.A. 2003: The ecological significance of symbiotic microorganisms in animals: perspectives from the microbiota of aphids. In Hails R.S., Beringer J.E. \& Godfray H.C.J. (eds): Genes in the Environment. $15^{\text {th }}$ Special Symposium of the British Ecological Society. Blackwell Science, Oxford, pp. 306-325.

Ekesi S., Shah P.A., Clark S.J. \& Pell J.K. 2005: Conservation biological control with the fungal pathogen Pandora neoaphidis; implications of aphid species, host plant and predator foraging. Agric. Forest. Entomol. 7: 21-30.

FERrari J. \& Godfray H.C.J. 2003: Resistance to a fungal pathogen and host plant specialization in the pea aphid. Ecol. Letters 6: 111-118.

FerRARI J. \& Godfray H.C.J. 2006: The maintenance of intraspecific biodiversity: the interplay of selection on resources use and on natural enemy resistance in the pea aphid. Ecol. Res. 21: 9-16.

Ferrari J., Müller C.B., Kraaijeveld A.R. \& Godfray H.C.J. 2001: Clonal variation and covariation in aphid resistance to parasitoids and a pathogen. Evolution 55: 1805-1814.

FinNey D.J. 1971: Probit Analysis. 3rd ed. Cambridge University Press, Cambridge, $x v+333$ pp.

Fuentes-Contreras E. \& Niemeyer H.M. 2000: Effect of wheat resistance, the parasitoid Aphidius rhopalosiphi, and the entomopathogenic fungus Pandora neoaphidis, on the population dynamics of the cereal aphid Sitobion avenae. Entomol. Exp. Appl. 97: 109-114.

Fuentes-Contreras E., Pell J.K. \& Niemeyer H.M. 1998: Influence of plant resistance at the third trophic level: interactions between parasitoids and entomopathogenic fungi of cereal aphids. Oecologia 117: 426-432.

Gallardo F., Boethel D.J., Fuxa J.R. \& Richter A. 1990: Susceptibility of Heliothis zea (Boddie) larvae to Nomuraea rileyi (Farlow) Samson, effects of $\alpha$-tomatine at the third trophic level. J. Chem. Ecol. 16: 1751-1759.

Gatehouse J.A. 2002: Plant resistance towards insect herbivores: a dynamic interaction. New Phytol. 156: 145-169.

Giles K.L., Berberet R.C., Zarrabi A.A. \& Dillwith J.W. 2002: Influence of alfalfa cultivar on suitability of Acyrthosiphon kondoi (Homoptera: Aphididae) for survival and development of Hippodamia convergens and Coccinella septempunctata (Coleoptera: Coccinellidae). J. Econ. Entomol. 95: 552-557.

GonzÁles W.L., Fuentes-Contreras E. \& Niemeyer H.M. 2002: Host plant and natural enemy impact on cereal aphid competition in a seasonal environment. Oikos 96: 481-491. 
Gosselke U., Triltsch H., Rossberg D. \& Freier B. 2001: GETLAUS01 - the latest version of a model for simulating aphid population dynamics in dependence on antagonists in wheat. Ecol. Model. 145: 143-157.

Gratton C. \& Denno R.F. 2003: Seasonal shift from bottom-up to top-down impact in phytophagous insect populations. Oecologia 134: 487-495.

Hajek A.E. \& Renwick A.A. 1993: Incorporation of Quercus rubra foliage into artificial diet alters development of a fungal pathogen of Lymantria dispar. Entomol. Exp. Appl. 68: 265-267.

Hemmati F., Pell J.K., McCartney H.A., Clark S.J. \& Deadman M.L. 2001: Conidial discharge in the aphid pathogen Erynia neoaphidis. Mycol. Res. 105: 715-722.

Hodgson D.J., Vanbergen A.J., Hartley S.E., Hails R.S. \& CORY J.S. 2002: Differential selection of baculovirus genotypes mediated by different species of host plant food. Ecol. Letters 5: 512-18.

Inyang E.N., Butt T.M., Doughty K.J., Todd A.D. \& Archer S. 1999: The effects of isothiocyanates on the growth of the entomopathogenic fungus Metarhizium anisopliae and it infection in the mustard beetle. Mycol. Res. 103: 974-980.

Kareiva P. \& SahaKLan R. 1990: Tritrophic effects of a simple architectural mutation in pea plants. Nature 345: 433-434.

Kessler A. \& BALdwin I.T. 2002: Plant-mediated tritrophic interactions and biological pest control. AgBiotechNet 4: 1-7.

McCullagh P. \& Nelder J.A. 1989: Generalized Linear Models. Chapman \& Hall, London, 511 pp.

MeEkEs E.T.M. 2001: Entomopathogenic Fungi Against Whiteflies: Tritrophic Interactions Between Aschersonia species, Trialeurodes vaporariorum and Bemisia argentifolii, and Glasshouse Crops. PhD Thesis, Wageningen University.

Milner R.J. \& SOPER R.S. 1981: Bioassay of Entomophthora against the spotted alfalfa aphid Therioaphis trifolii f. maculata. J. Invertebr. Pathol. 37: 168-173.

Montllor C.B., Maxmen A., Purcell A.H. 2002: Facultative bacterial endosymbionts benefit pea aphids Acyrthosiphon pisum under heat stress. Ecol. Entomol. 27: 189-195.

Paul N.D. \& Gwynn-Jones D. 2003: Ecological roles of solar UV radiation: towards an integrated approach. Trends Ecol. Evol. 18: 48-55.

Payne R.W. (ed.) 2003: The Guide to Genstat Release 7.1. Part 2: Statistics. VSN International, Oxford, UK.

Pell J.K., Eilenberg J., Hajek A.E. \& Steinkraus D.C. 2001: Biology, ecology and pest management potential of Ento- mophthorales. In Butt T.M., Jackson J. \& Magan N. (eds): Fungi as Biocontrol Agents: Progress, Problems and Potential. CABI International, Wallingford, pp. 71-153.

Poprawski T.J., Greenberg S.M. \& Ciomperlik M.A 2000: Effect of host plant on Beauveria bassiana- and Paecilomyces fumosoroseus-induced mortality of Trialeurodes vaporariorum (Homoptera: Aleyrodidae). Biol. Control 29: 1048-1053.

Raymond B., Vanbergen A., Pearce I., Hartley S.E., Cory J.S. \& HaILS R.S. 2002: Host plant species can influence the fitness of herbivore pathogens: the winter moth and its nucleopolyhedrosis virus. Oecologia 131: 533-541.

Schultz J.C. \& KeAting S.T. 1991: Host-plant-mediated interactions between the gypsy moth and a baculovirus. In Barbosa P., Krischik V.A. \& Jones C.G. (eds): Microbial Mediation of Plant-Herbivore Interactions. John Wiley \& Sons, New York, pp. 489-506.

Shah P.A., Clark S.J. \& Pell J.K. 2004: Assessment of aphid host susceptibility and isolate variability in Pandora neoaphidis (Zygomycetes: Entomophthorales). Biol. Control 29: 90-99.

Steinhaus E.A. 1949: Principles of Insect Pathology. McGrawHill Book, New York, 757 pp.

StiLing P. 1988: Density-dependent processes and key factors in insect populations. J. Anim. Ecol. 57: 581-593.

TAKabayashi J. \& Dicke M. 1996: Plant-carnivore mutualism through herbivore-induced carnivore attractants. Trends Plant Sci. 1: 109-113.

Tsuchida T., Koga R., Shibao H., Matsumoto T. \& Fukatsu T. 2002: Diversity and geographic distribution of secondary endosymbiotic bacteria in natural populations of the pea aphid, Acyrthosiphon pisum. Mol. Ecol. 11: 2123-2135.

Vorburger C., Sunnucks P. \& Ward S.A. 2003: Explaining the coexistence of asexuals with their sexual progenitors: no evidence for general-purpose genotypes in obligate pathenogens of the peach-potato aphid, Myzus persicae. Ecol. Letters 6: 1091-1098.

WALKER M. \& JONES T.H. 2001: Relative roles of top-down and bottom-up forces in terrestrial tritrophic plant-insect herbivore-natural enemy systems. Oikos 93: 177-187.

WILDING N. 1973: The survival of Entomophthora spp. in mummified aphids at different temperatures and humidities. $J$. Invertebr. Pathol. 21: 309-311.

Received July 24, 2006; revised and accepted January 9, 2007 